\title{
Sobre José Martí y su viva lección.
}

\author{
Al hombre ha de decirse lo que es \\ digno del hombre $y$ capaz de exal- \\ tarlo. \\ JOSE MARTI.
}

Colocados en medio del tiempo en que las palabras más puras no lo son sino resonando con los ecos profundos de la acción, los americanos evocamos ahora de diferente manera a los que crearon entre nosetros un poco de belleza, o a los que suscitaron un poco de emoción. Frente a sus figuras augustas, siempre tendremos que preguntarnos qué hicieron, además, de su vida. Y aquí tenemos una bella respuesta. Tenemos la JoséeMartí.

Los que en el vago territorio de la infancia leímos alguna vez su Edad de Oro y no pudimos olvidarla, querríamos haber hallado entonces su secreto final, lo que encerraba de a atenticidad, de cristalinidad, de fuerza grave y tierna esa prosa en la que tendremos que creer para siempre.

Si. hoy se nos respondiera que guardaba el humilde y cierto sentido de la vida, encontraríamos que se olvidaba mencionar el paraje heroico de su muerte. Y por allí comenzaríamos a encontrar el oculto camino. Porque a través de toda su obra y a lo largo de su vivir viril y emocionado, la vida y la muerte se entrelazarán como en una Iliada secreta y dulce, cuyo desenlace él anteladamente hubiera conocido. 


\section{VIDA IMINIADA DE JOSE IMARTI}

\section{LA PRIMERA ETAPA}

Hoy que, como en su Cuba natal, el héroe está en espiritu más cerca que nunca del corazón de las juventudes americanas, es válido recordar lo que advirtiera alguna vez Ventura García Calderón:

"ocurre con él-dijo-lo que con tantos hombres simbólicos: se escuchó mentar el nombre, que es programa y bandera; pero muy pocos recorrieron la obra magna. Martí es uno de los más ilustres y notorios desconocidos del Continente; y quizás la fama del apóstol ha perjuclicado a la del literato ( I )".

El Perú que sintió tan profundamente los anhelos de libertad por los que Martí vivió y murió, no puede olvidarlo. $Y$ esa etapa de violenta huz que se abrió para América cuando nació en La Hảbaña el fiño José Martí, el 28 cle enero de I853, no se cerró para nosotros con el final crepúsculo de sangre de Dos Ríos, aquél luctuoso ig de mayo de I895. Lo tenemos presente para que no nos deje olvidar el sentido de aquellas dos palabras en las que se enmarcó la vicla del Héroe: cultura y libertad.

Pocas son las figuras de nuestra historia americana tan dignas de amor, como la de Martí. En él está presente todo lo que hemos escogiclo para venerar, para admirar, para seguir. Todo aquello por lo que vale bien morir. $Y$ apareció a

(1) Páginas escogidas - JOSE MARTI - (prológo de Ventura García Calderón). - Garier, París. 
este lado del mundo para darnos a los americanos el valor de seguir adelante.

Cuando nace Martí todo parece ordenarse, como en un misterioso ritual, a preparar un gran sacrificio. Cuba pare-, cía exigirlo, su libertad, con la que tantos hombres soñaban en silencio. Acaban de caer López y Agüero. Cuba sangra y sueña. En Martí, hijo de padres españoles, tenía que levantarse pronto el llamado de la tierra, conmovedor, exigente, violento. En difícil elaboración de intensos dias y vigilantes noches, compartiendo el lugar de suave soledad de su pensamiento, va alzándose su pasión indeclinable: la de la libertad de Cuba. Y aunque Martí no fuera lo que exactamente llamamos un hombre de acción, veámoslo iniciar una vida $\sin$ tregua y $\sin$ reposo. Sacrificando ideales que quizás fueran demasiado grandes. Trabajando por los inmediatos, por los premiosos e intransferibles ideales de su pueblo antillano. Escribiendo y hablando sin descanso por ellos, como él dijera en su semblanza del Padre Las Casas. Su corazón profético ya selo habia advertido: "Para mî la patria no será nunca triunfơ, sino âgonía yl deber'verson

Su infancia, su juventud, son las de la mayoría de los escritores americanos. Génesis a veces dolorosa, siempre difícil, dura pugna del espíritu contra las fuerzas más oscuras. Duro triunfo, si llega alguna vez. Hay cuadros de luz; pertenecen a su infancia campesina, que habría de estudiarse a fondo algún día para explicar la influencia poderosa del paisaje antillano en la dulzura secreta y recia de su estilo. Niñez campesina y a la vez meditativa sus biógrafos nos pintan al niño leyendo aventuras en el ancho plenilunio d'el trópico: una vieja edición del Quijote, estancias de Fray Luis de León. Es la época de los primeros versos y también la de las pri- 
meras pugnas familiares. Vienen dias oscuros. La familia de Martí vá a La Habana y el héroe, a los trece años, entra a trabajar como un humilde dependiente. Es entonces que, como Simón Rodríguez en la de Bolivar, entra en su vida su maestro, el poeta Mendive. A su lado acude, rendido a veces por la fatiga del laborioso día. En su compa"ñía satisface la pasión de leer. Y su leal amistad lo acompañará en adelante.

A los dieciseis años Martí realiza en La Habana su primer trabajo revolucionario: un periódico clandestino a favor de la Revolución. Y sufre entonces su primera prisión, donde vislumbramos ya ese severo orgullo, intentando impedir que su madre, española, pida piedad para el rebelde.

Parte entonces desterrado a España, doncle inicia una nueva etapa, no monos dura y pobre: la etapa estudiantil. En la Universidad de Zaragoza obtiene primero el título de licenciado en filosofía y letras y luego el de licenciado en derecho. Viaja a Madrid y publica allí aquella emocianante oración, inmensa y pura elegía por las almas de los ocho estudiantes fusilados en Lac Habana en 1871. Estudia. Trabaja y sufre. Pero, sobreitodo, afina sub profundo senticlo de humanidad, su solidaridad con el sufrimiento y con la angustia del hombre, su vocación heroica.

En I874 logra salir de España y viajar a México, donde se reúne con los suyos. Nunca olvidará su permanencia en ese gran país fraternal, que le permitirá trabajar y vivir en la paz que tanto amara y de la que tan lejano lo mantuvo siempre su aceptado destino. Viaja después por Centro América y vuelve a Cuba después de firmadia la paz de Zanjón.

Respecto a ésta, su perspicacia y sus intuiciones de patriota lo hicieron diudar. Sabía que era ilusión creer en ella. Preveía su transitoriedad, la falsía que entrañaba. $Y$ se 
fortalecía en él la esperanza de los días pasados unida al propósito de seguir peleando por una Cuba libre y digna. Rehuye ingresar al partido autonomista, cancelando así toda posibilidad de representar a su patria en el parlamento español. $Y$, al tomar parte en una nueva conspiración, es nuevamente deportado a España. Aún no está maduro el héroẹ para el sacrificio. Continúa entonces su errancia por el mund'o.

Huyendo de España viaja, por la vía de Francia, nuevamente hacia 'América, a Nueva York. Se ocupa alli en preparar, con el General Calixto García, una nueva invasión para llevar la libertad a la Isla gimiente. Pero fracasa una vez más. Después de una breve permanencia en Venezuela parte otra vez hacia Nueva York y se establece allí definitivamente a fin de prepararse, en el silencio y en la soledad, para el definitivo combate y la definitiva gloria. Es ya I881. Inicia sus quince años de maravillosa labor, quince años que desembocarán en la gloria y la muerte.

El escritor magnífico, como en previsión de la breve etapa que resta recorrer a st vida, afana la tarea. Alcanza el más perfectól dominio del estilo y la forma. Su instrumento verbal se torna buíclo, increíblemente lleno de ecos inauditos, recorrido de chispas extranas, de dulces corrientes de emoción; viril y pleno. Aparece el poeta de los Versos Sencillos, el crítico de arte, el comentador literario. En el "Hour" neoyorquino escribe en su característico inglés, artículos plenos de sentido, que sorprendían y encantaban al lento y pesado lector de periódicos norteamericano. Y cuando el generoso Charles A. Dana le brindara las columnas de su cliario "The Sun", he aquí a nuestro Martí infatigable, ocupándose por igual de política europea, de historia americana, de arte, de literatura. Ganaba bien su amargo pan de desterrado. 
No le faltaron las tentaciones. ¿Cómo las resistió? Propuestas, homenajes. Su fama crecía y varias naciones americanas le ofrecían, junto con la seguridad económica, el melancólico y lejano ideal de un hogar sin zozobras. Triunfar de la débil naturaleza. Resistir, luchar siempre. Sus consignas fueron cumplidas. Y si pensamos que era humano, tendremos que asignar valor mayor a su repetido y secreto sacrificio. Como Charles Péguy, a quién tanto lo asemejan la pureza y el heró́smo, pudo decir de sí: "soy pobre...pobre". Pero tenía la riqueza de su corazón que relucía, viviente, en la amargura de sus noches de desterrado y en la angustia del triunfo que veía lejano. Y como de Charles Péguy dijera René Lalou, podría decirse de Martí; "es necesario medir la fuerza de las promezas que la tentación lanzó sobre él, para mejor admirar la belleza de su resistencia".

\section{LA LUCHA FINAL}

Este hombre exquisito que comienza a pisar los áspecros territorios de la lucha, el varón de paz que sólo afrontará la guerra como unl irictuscnecèsarioey doliente de la libertad, cierra desde entonces los lojes a todo, lo que no sea la pasión de su "Cuba natal.

Y comienza la pelea fuera del campo de batalla, la escaramuza sin plomo y sin sangre, más ruda muchas veces que la guerra misma. Combate con la frialdad, con la indiferencia, con la calumnia, con el deshonor. Combate infatigable, a menudo casi solo y aparentemente sin esperanzas. Pero él abriga úna secreta, la que le anunciaba que el momento de Cuba estaba próximo: el de trabajar por los que abanclonaban el trabajo común. El de luchar por los que arrojaban las armas. Y fulge su palabra brillante, sin descanso. Y escribe. Y prepara materialmente las batallas futuras, vincu- 
lando unos con otros los esfuerzos aislados. Y funda el Partido Revolucionario Cubano.

Su trabajo no ha de ser infructuoso. Al conjuro de su palabra llena de singular sentido, comienzan a agruparse los héroes casi desengañados de la revolución pasada, los antiguos caudillos, los macheteros d'el Oriente. Y los bronceados guerreros de ayer cerraban filas ya con las nuevas generaciones de cubanos, en las que el héroe había puesto tanta esperanza.

Aún deberían atacarlo la traición y el desengaño. Y cuando son capturados los barcos listos para conducir a Cuba armas y soldados; cuando adviene sobre Martí su verdadera noche triste, tras el primer embate del dolor, se dirige a sus fieles amigos, a Tomás Estrada Palma, a Benjamín J. Guerra, a Horacio S. Rubens, a Gonzalo de Quesada y Aróstegui, y con la voz quebrada por la emoción les pregunta: “¿Tienen ụstedes todavía fé en mí? ¿Me ayudarán ustedes otra vez?".

Si, tienen fe. Cuba lo ayudará. E1 intuye que la supremo. lucha se acerca.OViaja aCSanto Domingo con los Generales Collazo y Rodríguezcpiarallentrevistarse con Máximo Gómez, el viejo león de Montecristi, aquél nobilísimo anciano a quien

“. . . si va por la calle le dan paso todos; si hay baile en casa del Gobernador, los honores son para él, y la silla de la derecha, y el coro ansioso de oírle el cuen. to breve y picaresco".

A este hombre de temple sin igual se acerca Martí para comprometer su brazo fuerte y su mirada de águila, para la lucha próxima; sin osar prometerle, en lo futuro, nada

(2) Máximo Gómez -JOSE MARTI - (Ob. cit.). 
más que "la probable ingratitud de los hombres". Martí ha narrado la entrevista en párrafos nobles, dignos de engarzarse en un inmensa Iliada americana:

"Allí-dice-esquivándose a los halagos fraternales de los montecristeños, dió el General cita, con su pañuelo al cuello y una mirada que se ve en hombres pocas veces, a un cubano que por primera vez sintió entonces orgullo, para ver el mejor modo de servir a Cuba oprimida, sin intrusión, ni ceguera, ni soberbia. Un pueblo entero pasó por aquél desván desmantelado; y sus derechos. para no hollar ninguno, y sus equivocaciones, para no recaer en ellas, y sus recursos, para emplearlos con seguridad, y sus servidores, para abrazarse a todos, y los infieles mismos, para no reconocerles más que la grandeza pasada y la posibili dad de arrepentirse". (3).

Comienza ya I895. En Nueva York se ultiman los preparativos para la expedición. Guba. tensa como una flecha en el arco. esperr. Esperan todns. con las armas en la mano,

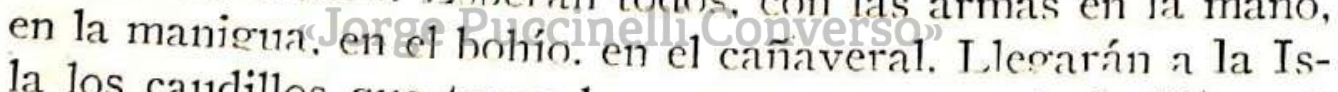
la los caudillos aue traen la nueva esperanza de la libertad. No importa que la traición haya hecho fracasar una vez más aquél Plan de Fernandina, que incluía la participación de las fuerzas que el gran Antonio Maceo había reuniclo en Costa Rica. Martí es el nervio mismo, la imagen misma de la nueva esperanza. Y a su lado tod'os han vuelto a reunirse. $\mathrm{El} 25$ de marzo el Héroe redacta y firma, en unión de Máximo Gomez el histórico Manifiesto de Montecristi, en el que expone las causas que mueven a los cubanos a empuñar las armas, y la política de guerra que observará la Revolución renacien-

(3) Ibid. 
te. Escribe al mismo tiempo a Federico Henríquez y Carvajal la carta inolvidable que se considera su Testamento Político.

"Donde esté mi deber mayor, adentro o afuera, allí estaré yo-dice Martí-. Acaso me sea dable u obligatorio, según hasta hoy parece, cumplir ambos. Acaso pueda contribuír a la necesidad primaria de dar a a nuestra guerra renaciente forma tal, que lleve en germen visible, sin minuciosidades inútiles, todos los principios indispensables al crédito de la revolución y a la seguridad de la república".

$\mathrm{Y}$ añade:

"La dificultad de nuestras guerras de independencia y la razón de lo lento e imperfecto de su eficacia ha estado, más que en la falta de estimación mutua de sus fundadores y en la emulación inherente a la naturaleza humana, en la falta de forma que a la vez contuviese êlospiritucle redención yecoro que, con suma activa deeímpetus deipureza menor, promueven y mantienen la guerra, y las prácticas y personas de la guerra" .(4).

E1 I. ${ }^{\circ}$ de abril Martí escribe a Gonzalo de Quesada y Aróstegui la carta que se considera su Testamento Literario. Y esa misma noche embarca en una pequeña goleta, en compañía de los Generales Máximo Gómez y Angel Guerra, de Paquito Borrero, César Salas y el dominicano Marcos Rosario. Parten de una caleta desierta, cercana a la frontera con Haití, y se internan en un mar infestado de buques de cit.).

(4) Carta a Federico Henríquez y Carvajal - JOSE MARTI - (Ob. 
guerra enemigos. Instrumento de una nueva traición, el capitán del barco los conduce a Inagua, donde instiga a la tripulación a desertar. Los viajeros tienen un momento de desesperación. ¡No llegarían nunca! Y Cuba espera en silenciosa tensión, vela en la noche, con los ojos abiertos, la larga vigilia de la libertad. No habría mejor acicate para el Héroe. Martí contrata un barco que los llevará hasta Cabo Haitiano. De alli salen el 9 de abril y el i i de abril a las ocho de la noche, aquel barco desliza un pequeño bote por una de sus bordas. Desciende sobre el mar agitado. Reman sus ocupantes, reman febrilmente hacia la costa oscura. Martí es uno de ellos. Desembarcan en Playitas, alrededor de las once de la noche. Las fuerzas cubanas de esa región los reciben en triunfo. Cumplía, pues, su palabra. El Héroe estaba en su puesto, y esta vez para siempre.

E1 15 de abril es proclamado Mayor General ante el Ejército Libertador. Martí ha narrado la escena casi épica con humildes palabras heroicas. Allí, en cambio, ante los rudos soldados, hechos a todas las fatigas y las luchas, vibrante en la rudia jontreva fraternidadade las armas, Martí pronuncia una de sus arengas más bellas, El 5 de mayo se entrevista en La Mejorana con los Generales Máximo Gómez y Antonio Maceo. Comienza a preparar su viaje a Camagüey. Es necesario encender la llama sagrada de la guerra de la libertad en las provincias centrales. Es necesario actuar, trabajar. Pero también era necesario morir y en la quietud de la noche del trópico, como para un héroe de Rilke, nacía y crecía su muerte, preparando el encuentro final.

Los enemigos, guiados por un espía, rodean el campamento patriota. El General Gómez, seguido de sus mejores jefes, parte a batirlo. Y pide a Martí que aguarde su regreso. Pero es el ig de mayo de I895, en el paraje de Dos Ríos, 
y la hora hạ sonado. ¿Cómo volver atrás? ¿Cómo desfallecer? Se delínea el cuadro: "Bajo las palmas, sobre un caballo blanco, cara al sol", como él lo había deseado. Así habia querido morir. Y todo está listo para que se cumpla su antiguo anhelo. Es en Dos Ríos, donde el Cauto, el único gran río de la Isla, abre sus brazos entre las verdes lomerías, donde se alza la caña de azúcar sobre la manigua rumorosa.

Comienza el vocerío de la batalla. Y mientras Gómez ataca, aniquilándolo, uno de los flancos españoles, Martí avanza a la cabeza de unos cuantos hombres. Su caballo lo lleva como una centella, iniciando la carga soñada. Nada falta. Las balas buscan su corazón heroico. Cae José Martí. Gonzálo de Quesada dijo:

"... el plomo, entrando debajo de su barba, desfiguró la boca firme, quemó el espeso bigote y silenció para siempre su lengua áurea" (5)

Duerme en Santiago de Cuba, hacia la parte oriental de la Isla. Pero vivelen cada uno de tos Zatidos del corazón de sus hombres, en el cantan de las muchachas cubanas, en el aire que mueve las altas palmas costeras, en cada lágrima, en cada música, en cada rumor, como los héroes clásicos entre los que ha encontrado su lugar perdurable.

\section{SOBRE UN CULTO IMARTIANO EN AMERICA}

Como de Bolivar, podría decirse de este hombre las palabras exactas del humilde cura peruano: con los siglos crecerá su gloria como la sombra cuando el sol declina.

(5) Reseña biográfica de José Martí-GONZALO DE QUESADA Y AROSTEGUI - (publicada en inglés en The War in Cuba, obra de propaganda de la causa cubana editada en 1896 por Liberty Publishing Press). 
En el pasado mayo se cumplieron cuarenticinco años del combate matinal de Dos Ríos, y los americanos pensamos aún en la maravillosa cosecha que hubiéramos debido a la madurez de su pensamiento en la álgida cumbre de esa vida que el sacrificio hizo tan breve.

Martí sintió a América como muy pocos de sus hijos, uniendo en claros términos la intuición con la pasión. Más que ninguna es la suya la historia de una pasión americana. Como supo mirarla con la dolorosa lucidez de los que nada esperan, esta mirada se colmó por el contraste del sacrificio próximo, con la más fundada esperanza.

América comienza a pagar el homenaje emocionadio que pide la memoria de éste a quién con derecho puede llamar el último de sus Libertadores. Partiendo de su Cuba natal vá extendiéndose como una gran ola continental el culto martiano. Culto a su mensaje, a su obra, a su vida. Pero no hay que olvidar que el culto es rito, es decir forma. Y la luz de Martí nos exige seguirla, en esencia y pasión, más allá del vago dominio formal.

"Todo el que fleva luz se quedă, solo"a dijo en verso lleno de heroica certeza. Pero no lo han dejado solo las nuevas generaciones americanas. $Y$ así los años últimos dicen bien claro que el culto a Martí no podrá ser ya ni incondicional ni ciego, pues todo lo que lleva en sí el sello noble de lo nuevo, de lo que en América adviene puro y bien intencionado, elevará por encima de toda acción el nombre de Martí. Y esto encerrará la mejor de las promesas, nacida del honor de. seguirlo.

Hoy que han vuelto a agitarse sobre nuestros pueblos las luchas por la libertad, está vigilante sobre nosotros este espíritu heroico que todo lo dió por una libertad' sin condiciones, tan digna del hombre que pudo pedir en holocausto una vida como la suya. 
En nada se engañó cuando dijo:

"En pueblos compuestos de elementos cultos e incultos, los incultos gobernarán, por su hábito de agredir y resolver las dudas con su mano, allí donde los cultos no aprendan el arte del gobierno. La masa inculta es perezosa y tímida en las cosas de la inteligencia, y quiere que la gobiernen bien; pero si el gobierno le lastima, se lo sacude y gobierna ella. ¿Cómo han de salir de las universidades los gobernantes, si no hay universidad en América donde se enseñe lo rudimentario del arte del gobierno, que es el análisis die los elementos peculiares de los pueblos de América?" (6)

Todas sus soluciones son válidas lioy. Como para Eugenio María de Hostos, América significó para él un hogar sin fronteras, y una responsabilidad profunda y grave. Y a esas convicciones hay due atribuir el casi profético sentido de sus observaciones y desus juicios sobre nuestros pueblos.

Como el Santiago mítico dé las leyendas peninsulares, él estará presente en las nnevas batallas. con cargas épicas como la de Dos Ríns animando la dos vacilantes, a los indecisos, a los tibios de corazón. Y como un Campeador americano, ganará después de muerto, para su Cuba y para su América, todo combate que se libre por la cultura y por la libertad.

\section{PARA UNA IMAGEN LITERARIA DE MARTI}

\section{UNA PROSA SIN PAR}

José Martí amó sobre todas las cosas su oficio de escribir. Era tan fuerte en él su necesidad de expresar, que cit.).

(6) Carta a Federico Henríquez y Carvajal-JOSE MARTI-(Ob. 
aún hoy, sobre la creciente grandeza de su gloria civica, no podemos olvidar que fué una de las primeras plumas americanas.

Una y otra vez, meditando sobre el sino que lo hizo vivir en nuestro mundo americano, surge la comparación que lo acerca a Charles Péguy. A través del tiempo en el que Martí lo precediera, el francés se asemeja al cubano en la fraternidad común de la verdad, en el cristianismo esencial, fuera de la Iglesia y aún contra la Iglesia. Y en ese igual amor desesperado a su duro destino de escritores libres, de soldados de la inteligencia.

$\mathrm{Y}$ aunque la muerte también los asemeje en la misteriosa preparación guertera de su escenario último, detengámonos sólo en lo que previamente surge al observar la imagen intelectual de Martí en su prosa magistral, rica, henchida de sentido.

Se ha dicho que fué antes que nada un orador. Los que lo oyeron, no lo olvidaron nunca. Se hablaba de st1 voz "suave, extrañamente musical, que no tenía el sonido de una fanfarria guerrera escuchada en an campo de batalla, sino la armonía deliciosa Jde Ein Pquinteto de César Franck". (7). Máximo Gómez dijo de él: "era un mago, todo lo podía con la palabra. $\mathrm{Y}$ hemos de creer asimismo a Manuel de la Cruz: (8).

". . lograba despertar la idolatría, y siendo orador de estilo elevado, esencial y profundamente literario, quinta esenciado y frecuentemente obscuro, era tal el tono, el color, la fuerza de su palabra, que arrebataba a quiénes no podian apreciar en análisis exacto el mérito extraordinario de sus párrafos".

(7) Evocación de Martí - J. M. VARGAS VILA. - Barcelona, marzo,

(8) José Marti - M:ANUEL DE LA CRUZ. 
Su prosa escrita es, sin embargo, lo que más nos ha dicho de Martí a los americanos agraviados por el tenaz aislamiento de nuestros países, por el mal del desconocimiento mutuo. Alta prosa de imágenes perfectas, prosa de oculto y misterioso colorido, prosa de tremendo trabajo y aparición naturalísima. De esa prosa en la que encontrará Gabriela Mistral-itan filial de Martí, tan Martí ella mismaj- la esencia, el sentido de América, dijo Miguel Angel Carbonell:

"Como los colores en la paleta del artista, las figuras retóricas estaban ordenadias en su mente; y así le fluían, al declamar o al escribir, siempre con matematicidad asombrosa, ora el apóstrofe, haciendo cobrar vida lo inanimado y como arrancando nuevos - juramentos de independencia a los que cayeron en la lucha que no pudo coronar la victoria; ora la perífrasis que suaviza el ataque personal, envolviéndolo en conceptismos agudos, y rehuye lo feo de la repetición; ora la onomatopeya, que deja escuchar el ruido de las armas en fos combates, yalas órdenes imperativas dedosejefescynel lielinchar de, los corceles en las cargas; ora el polisindeton, que amalgama los períodos como en el pentagrama wagneriano se juntan los inarmónicos; ora la imagen, que rompe la concreción de la idea, y la dilata y la ornamenta con sus ramilletes de espuma". (9)

Esa bella prosa serena, que fué tantas veces su arma de combate, sirvió también al Apostól para los menesteres de la belleza y de la paz. Busca por su intermedio la ternura, al dedicar a su hijo los versos de Ismaelillo:

(9) Discurso pronunciado en la "Sociedad de Conferencias", el 25 de febrero de 1922 - MIGUEL ANGEL CARBONELL. - Habana. 
"Hijo: espantado de todo me refugio en ti.- Tengo fé en el mejoramiento humano, en la vida futura y en tí.- Si alguièn te dice que estas páginas se parecen a otras páginas, diles que te amo demasiado para profanarte asi.- Tal como te pinto, tal te han visto mis ojos.-Con esos arreos de gala te me has aparecidio.Cuando he cesado de verte en una forma he dejado de pintarte.-Esos riachuelos han pasado por mí corazón.-Lleguen al tuyo". (IO).

Es la prosa toda de La Edad de Oro, de las semblanzas de Bolivar, de San Martín, de Páez, de sus gloriosos compañeros Máximo Gómez y Antonio Maceo; las frases refulgentes con que nos habla del Padre Las Casas, de Julián del Casal, de Heredia, de Oscar Wilde, de Walt Whitman, iprosa de las grandes y heroicas horas y también la del diario acontecer, de lo humilde y de lo cotidiano! Su alma noble y viril se transparenta en esas líneas de tensión admirable, a las que parece imposible añadir ni restar palabra alguna. Decía del Padre Las Casas:a de Letras

\section{"Jorge Puccinelli Converso»}

"No se puede ver un lirio sin pensar en el Padre Las Casas, porque con la bondad se le fué poniendo de lirio el color, y dicen que era hermoso verlo escribir con su túnica blanca, sentado en su sillón de tachuelas, peleando con la pluma de ave porque no escribía de prisa". (I I).

$\mathrm{Y}$ cuando evoca a Whitman, "este poeta viejo, este an'ciano divino":

(10) Ismaelillo-JOSE MARTI.

(11) El Padre Las Casas - JOSE MARTI - (Ob. eit.). 
" Oh, no! Walt Whitman habla en versículos, sin música aparente, aunque a poco de oírla se percibe que aquello suena como el casco de la tierra, cuando vienen por él, descalzos y gloriosos, los ejércitos triunfantes".

Y más adelante:

“... señalando a los tiempos pasmadios las colmenas radiantes de los hombres que por los valles y cumbres americanos se extienden y rozan con sus alas de abeja la fimbria de la vigilante libertad; pastoreando los siglos anigos hacia el remanso de la calma eterna, aguarda Walt Whitman mientras sus amigos le sirven en manteles campestres la primera pesca de la Primavera" (I2).

De Páez dice:

"Nadie comenzó su vida en mayor humildad, ni la ilustró conil más dotes de aquellas sublimes que aparecen con el misterio de la vicla venir a los hombres privilegiados del espiritu mismo de la tierra en que nacen". (I3)

¡Prosa de Martí, a la vez instrumento de paz y buída lanza guerrera! ¡Prosa de dulzura y de tonante llamamiento al combate! ¡Prosa para los niños que sonríen y también para los guerreros que mueren! Es imposible evocarla sin emoción. América recogió con respeto la revelación encerrada en cada línea, la pasión que empapó cada letra. En la prosa sagrada de Martí, forjada de flores y de ar-

(12) Walt Whitman-Jose Martí - (Ob. cit).

(13) Páez - JOSE MARTI-(Ob. cit.). 
dorosa sangre reciente, están escritos para siempre los intensos mensajes que no podremos en adelante desoír ni olvidar.

\section{ECO TERRESTRE DE SU POEsía}

"Poesía no es de seguro, lo que corre con ese nombre: sino lo heroico y virgíneo de los sentimientos, puesto de modo que vaya sonando y lleve como alas; o lo florido y sutil del alma humana y lo de la tierra y sus armonías y coloquios; o el concierto de mundios en que el hombre sublimado se anega y resplandece". (I4). No hay aquí una Arte poética de Martí. No es la proclama de una escuela. El fué uno de los que describiera Thomas de Quincey, en carta dirigida a Bernard Barton: uno "de aquellos que llevan alguna música en sus almas". Fué de "los que a nadie pidieron prestados sus versos". Y si evocamos la lenta y fuerte rima que forjó para el poema de su vida, preparandio $y$ torneando con amor la sangrante estrofa final de Dos Ríos, nos explicaremos por qué fué más precaria, menos plena y definitiva sut obra poétics, frente a la del prosista y el orădore Tambiẻnl dijo algún día:

"No han de ser los versos como las rosas centifolias, todas llenas de hojas, sino como el jazmín de Malabar, muy cargado de esencias". (15).

$\mathrm{Y}$;siguió rectamente sus propias mandamientos de simplicidad, para hacer una poesía del hombre para el hombre, una poesía del espíritu a ras de la tierra. En las resonancias de su verso hallamos a veces a Santa Teresa, a

\footnotetext{
ción (14) Flores del Destierro - JOSE MARTI - Habana, 1932 - Introdue(15) Ibid.
(15onzalo de Quesada y Miranda.
} 
veces a Fray Luis, pero siempre al poeta de los Versos Sencillos, al que para la amistad y para la insidia guarda el mismo plantel de rosas:

"Cultivo una rosa blanca

en abril como en enero

para el amigo sincero

que me da su mano franca.

$\mathrm{Y}$ para el cruel que me arranca

el corazón con que vivo,

cardo ni oruga cultivo

cultivo una rosa blanca".

Ese era, literalmente, el José Martí que amamos: el caballero sin miedo y sin tacha, caballero del amor sin desmayos y paladín de la rosa blanca de la vida.

En Ismaelillo, en las Poesías, en sus Versos de Amor, en las Flores del Destierro, es el mismo poeta, directo y conmovedor, casi sin artificios, tan sincero como en su prosa cle diamante, delirio magno de creación. "La Niña de Gua.* temala" tratará de perennizar un episodio auténtico de la vida sentimental de Marti, tan poco estudiada:

"Quiero a la sombra de un ala

Contar este cuento en flor:

La niña de Guatemala

La que se murió de amor".

La patria, el paisaje antillano, la mujer, son sus temas primeros. Siempre bajo el signo de lo simple y lo bello, su poesía utiliza metros y formas casi populares, comunes, donde brilla mejor la delicadeza de su creación, la flor de sentido y vida que vive en sus poemas: 


\section{- $196-$}

"Ganado tengo el pan: Hágase el verso

Y en su comercio dulce se ejercite..."

Y dice a Cecilia Gutiérrez Nájera Maillefert, la hat del gran poeta mexicano:

"En la cuna sin par nació la airosa

Niña de honda mirada y paso leve,

Que el padre le tejió de milagrosa

Música azul y clavellín de nieve".

Creyó en la magia innumerable de la poesía, aunque ei intenso ejercicio de su vida no le dejara el reposo exigiclo para una pasión cardinal Pensâba:

"¿Quién es el ignorante que mantiene que la poesía no es indispensable a los pueblos? Hay gentes de tan corta vista mental que creen que toda poesía acaba en la cáscara. La poesía que congrega o disgrega, que apuntala ojo derriba clas armas tquesclá o quita a los hombres la fe 9 el aliento, es más necesaria a los pueblos que la muclustria misma, pues esta les proporciona el modo de subsistencia, mientras que aquélla les dá el deseo y la fuerza de la vida". (I6)

Será en una estrofa muy breve donde José Martí, como Péguy, forjará su epitafio de soldado de la libertad. Dice sólo asi, en sus cuatro versos:

"Yo quiero cuando me muera

Sin patria, pero sin amo,

tas (16) Poesias - JOSE MARTI - Habana, 1928 (estudio preliminar y notas por Juan Marinello). 
Tener en mi losa un ramo

De flores, y una bandera”.

Los tiene ahora. Más allá de las flores que velan su sueño de héroe fatigado por hazañas demasiado grandes, tiene la patria cubana que supo crear, y su bandera de azulencas bandas y palma solitaria y sutil.

\section{LA LECCION DE MLARTI}

$\mathrm{Su}$ valor, la pureza de sus propósitos, el ardiente estoicismo de su sacrificio le señalan un hermano en nuestro tiempo: Charles Péguy. Como se dijo de éste-con exactitud que conmueve, porque los separaron el espacio y el tiempopuede decirse de Martí que el poder de su misticismo pudo quizás alzar en el fondo de su alma cierta forma de desprecio hacia el mundo moderno, que lo envilece todo, hasta la misma muerte. Y que ese mismo poder le permitió permanecer hasta el fin, pese a las amarguras y a las decepciones, "una alma republicana".

América lo precisa asi, siempre, para rectificar los pasos errados, o "el corazón quie desfâlecer. O" para cerrar el camino a las fuerzas adversas que muchas veces han intentado ya destruír todo aquello que amó.

Su lección es la lección de la inteligencia fértil frente a la inteligencia estéril. La lección del desinterés y del herósmo a todo trance, alli donde todo conspira a aniquilarlos, donde surge como un negro convenio su negación constante.

Democracia, cultura, libertad, han sido entre nosotros, en la penosa infancia americana, sólo palabras grandes y elusivas, que la refracción de nuestra realidad ha desfigurado y traicionado a menudo. El las amó como a su pueblo mis- 
mo, como a razón primera de su vida y justificación de stt muerte. Y algún día nos revelará su secreto profundo: 10 que lo sostuvo para creer hasta el fin en un ideal aparentemente inasequible, engañoso y lejano, hasta hacerlo el eje cardinal de su labor terrena.

$Y$ porque amó la paz del hombre libre-tan diferente de la paz a cualquier precio que hoy vemos perecer-, y porque hizo la guerra para ganar esa paz valerosa a los que amaba, le es también aplicable lo que se dijo del Péguy que cantaba la necesaria guerra:

“. . su segunda lealtad, que es mental tanto como moral, consistió en tratar la guerra misma, al hacerse inevitable, como la guerra y nó como la paz". ( I 7).

Y como Péguy, poeta y soldado de la dulce Francia, quiso para sí la muerte del soldado, morir "por la tierra. carnal", "por salvaguardar las casas paternales". Martí cumplió su antiguo sueño después de haber siclo para su Cuba, como ninguno.

"el más ardiente segador en tiempo" de las mieses, el cantor más ardiente a la hora de cantar". ( I8).

José Alvarado Sánchez.

(17) Charles Péguy - RENE LALOU - París, 1924. (Histoire de la Littérature Française contemporaine).

(18) Heureux...., de la OEUVRES COMPLETES de CHARLES PEGUY nrf, París, 1916. 